\title{
Physical-Mechanical behavior and water-barrier properties of biopolymers-clay nanocomposites
}

\author{
Heidy Lorena Calambas ${ }^{1+}$, Abril Fonseca ${ }^{2,3+}$, Dayana Adames ${ }^{4}$, Yaneli Aguirre-Loredo ${ }^{2,3 *}$ and Carolina Caicedo ${ }^{5 *}$
}

1 Grupo de Investigación en Desarrollo de Materiales y Productos, Centro Nacional de Asistencia Técnica a la Industria (ASTIN), SENA, Cali, 760003, Colombia; hlcalambas@misena.edu.co (H.L.C.)

2 Centro de Investigación en Química Aplicada (CIQA), Blvd. Enrique Reyna Hermosillo 140, Saltillo, Coahuila 25294, Mexico; abril.fonseca@ciqa.edu.mx (A.F.-G.), yaneli.aguirre@ciqa.edu.mx (Y.A.)

3 CONACYT-CIQA, Blvd. Enrique Reyna Hermosillo 140, Saltillo, Coahuila 25294, Mexico.

4 Semillero de Investigación en Química Aplicada (SEQUIA), Facultad de Ciencias Básicas, Universidad Santiago de Cali, Pampa linda, Santiago de Cali, 760035, Colombia; yicel.adames00@usc.edu.co (D.A)

5 Grupo de Investigación en Química y Biotecnología (QUIBIO), Facultad de Ciencias Básicas, Universidad Santiago de Cali, Pampalinda, Santiago de Cali 760035, Colombia; carolina.caicedo03@usc.edu.co (C.C.)

+These authors contributed equally to this work and should be considered as co-first authors.

*Corresponding authors: yaneli.aguirre@ciqa.edu.mx; carolina.caicedo03@usc.edu.co

\begin{abstract}
The preparation of new materials based on starch for the development of biodegradable packaging is increasing, however, the poor properties of this biopolymer for this application causes an area of opportunities for the improvement of water vapour permeability (WVP), mechanical properties, thermal properties, hydrophilicity, water absorption, among others. Hence, starch has been combined with other polymers such as polyvinyl alcohol, which has shown an improvement in the mechanical properties of starch, also, the use of clays suggests that the properties of response to water can be improved. Therefore, in this work, the preparation and characterization of starchPVA-nanoclay films prepared by solvent casting is reported. The results obtained suggest that the sonication of nanoclay is necessary to reach a good dispersion, which promotes a strong interaction among starch-PVA-nanoclay. In addition, the properties of WVP and mechanical properties of films improved with incorporation of nanoclay, the concentration of $0.5 \% \mathrm{w} / \mathrm{v}$ of nanoclay showed to be the best concentration due to concentrations of 1.0 and $1.5 \% \mathrm{w} / \mathrm{v}$ were poorer than $0.5 \% \mathrm{w} / \mathrm{v}$. Accordingly, the successful incorporation of nanoclays into the matrix starch-PVA suggests that this material is a good candidate for use as packaging.
\end{abstract}

Keywords: Biodegradable polymers; Nanocomposite; Ultrasound-assisted; Mechanical properties; Montmorillonite

\section{Introduction}

In recent years there has been a generalized increase worldwide in the interest of society in the use of plastic materials that are more environmentally friendly; this has led to an increase in the number of research and development of polymers of organic origin. These new materials are intended to be a viable option to replace conventional petroleumderived plastics, whose main problem is the long degradation or disintegration time [1, 2]. One of the most promising natural polymers for developing biodegradable packaging materials is starch, mainly due to its high availability in nature, low cost, and short periods of degradability [3].

Although starch is abundantly available in nature, this polymer presents some challenges or disadvantages that must be faced if it is to be used as a raw material to obtain new sustainable packaging. Materials based on pure starch have been shown to have a weak mechanical performance, high solubility in water, and a poor barrier to gases, which makes them an unviable option to perform as packaging. However, when certain additives such as a plasticizer are added to the starch, the material becomes thermoplastic, 
which improves its processing and the functional behavior of the resulting material [4]. A plasticizer increases the flexibility of starch-based materials due to reducing the interaction of polymer-polymer hydrogen bonds, improving interfacial adhesion, and decreasing intermolecular binding sites in the crystalline regions of the granules of starch [5].

Despite the scientific and technological advances that have been developed to improve the physical-mechanical properties of thermoplastic starch (TPS), the materials continue to present some challenges that limit their applicability due to their high susceptibility to humidity and the process of retrogradation [6]. To overcome these deficiencies, different strategies have been implemented, among which the mixture of starch with other less hydrophilic polymers to obtain materials with better properties stands out. Some mixtures of TPS with polyvinyl alcohol (PVA) have been evaluated, which have generated materials with a gas barrier behavior and improved mechanical performance and a significant decrease in their water absorption capacity compared to pure starch materials. In the study carried out by Gómez-Aldapa et al., biodegradable films of potato starch and PVA were developed by the casting method, where it was shown that the addition of PVA significantly improved the permeability to water vapor and the mechanical properties of the films, properties with favorable results that make them a viable option for use as food packaging or packaging [7]. In addition to providing an improvement in the physicomechanical properties of starch-based films, the incorporation of PVA has been shown to generate important stability to the polymeric matrix, which inhibits the physical changes caused by the aging of the material, which is a critical parameter to consider in this type of materials [8].

In addition to resorting to the development of mixtures with other polymers, the improvement of starch-based packaging materials has been sought with the help of nanotechnology. In this sense, it has been observed that some nano-sized additives added at low concentrations can generate significant improvements in the mechanical, thermal, optical, and physicochemical properties of the materials compared to the pure biopolymer, all this without compromising their biodegradability. The use of reinforcing materials with nanometric particle sizes favors a more homogeneous dispersion of these, increasing the specific surface of reinforcements such as nano cellulose and nanoclays; these materials also exhibit improved thermal, mechanical, and barrier properties when reinforcing concentrations used are lower ( 1 to $5 \%$ by volume) than when using reinforcements of micrometer size or higher [9-13].

Recent research has focused on a specific type of reinforcement material, clay nanoparticles, which when added to TPS improve the mechanical performance of this polymer, generating materials with higher resistance to tension and toughnesss [14-18], as well as an improvement in the hydrophilic behavior of natural polymers, since the dispersed clay layers delay the diffusion of water molecules through the structural matrix due to the formation of a tortuous path for the permeant, making its diffusion difficult and making the material a better barrier to gases $[5,18,19]$. Montmorillonite (MMT) is the most widely used natural clay, it is a layered silicate that is characterized by having a moderate negative surface charge. The typical crystalline chemical structure of MMT consists of two tetrahedral layers of silica interspersed with octahedral layers of shared edge of magnesium or aluminum oxide, forming a two-dimensional mesh with a thickness of $1 \mathrm{~nm}$. MMT has been widely investigated due to its complex structure in the form of layers, which gives it high absorption capacity, good chemical stability and the possibility of exchanging ions $[20,21]$.

It has been reported that the final behavior of the nanocomposite material depends to a great extent on the form of interaction of MMT with the polymer, that is, if it is in exfoliated or intercalated form. Intercalation occurs when polymer chains are embedded between clay layers, resulting in a multilayer polymer-clay sheet structure. While in the exfoliated form, the silicate layers of the nanoclay have entirely separated and are individually dispersed throughout the polymer matrix [22], which results in a greater surface area, promoting higher interaction between the MMT and the structural polymer matrix [23]. Some studies have shown that conventional plastic processing techniques such as 
thermoforming, casting, or melt mixing, do not achieve complete exfoliation of the nanoclay, so the interaction of MMT with the polymeric matrix only occurs in an interspersed form [24-26].

According to the above, it is necessary to propose new biodegradable polymeric materials with improved mechanical and barrier properties. The use of nanoclays is seen as an excellent option to reinforce these materials; however, it is necessary to generate an ideal process that promotes a better dispersion of these nanomaterials. This new information could facilitate the development of new active packaging with mechanical and gas barrier performance that can compete with plastics of synthetic origin. In this study, biodegradable films based on thermoplastic starch/polyvinyl alcohol (PVA) reinforced with montmorillonite nanoclay (MMT) at different proportions were developed, processed by solvent casting, with and without the support of ultrasound, to evaluate the effect of this on the physical-mechanical properties of materials as a possible alternative as environmentally friendly food packaging.

\section{Results}

\subsection{Surface morphology by Light optical microscopy}

To appreciate the surface morphology of the SP/PVA composite films, they were observed in a conventional light optical microscope. According to the micrographs presented in Figures $1 b$ and $5 c$, it was observed that the film samples presented a surface with a slightly even appearance in each of the MMT formulations, however very different from that observed in the sample without nanoclay (Figure 1a). However, not all films had the same appearance; the formulation corresponding to Figure $5 \mathrm{~d}$ showed a less homogeneous surface behavior. Variations in the depth of the surface area were observed, with a slightly rough appearance in films containing 1.5 MMT (Figure 1d).

When the filmogenic solutions are treated with ultrasound, a significant change is observed in the surface morphology of the resulting films, as can be seen in Figures 1a-g. This behavior can be attributed to an efficient dispersion of the MMT-Na nanoclay in the SP polymer matrix, which is a significant indicator of the effectiveness of the treatment and could be seen as an improvement in the functional properties of the nanocomposite films. 


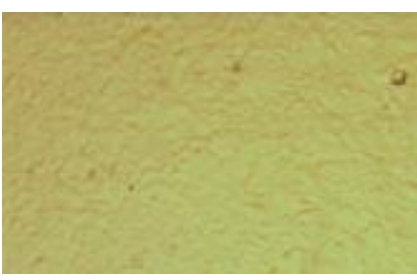

(a)

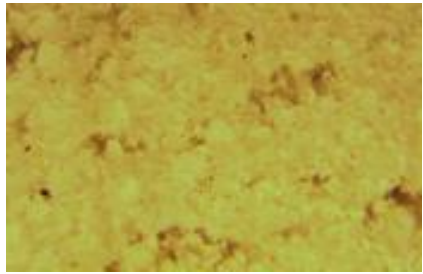

(b)

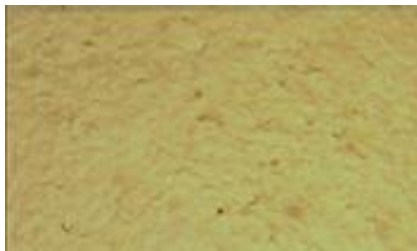

e)

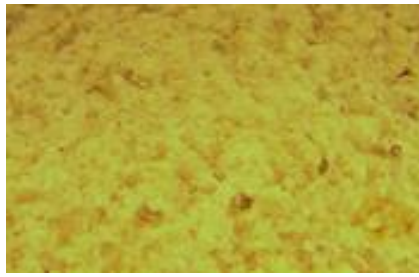

(c)

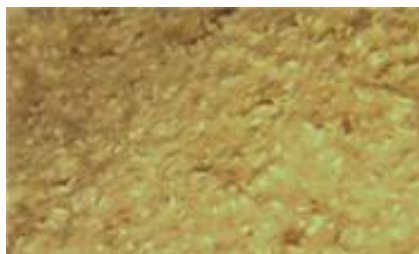

f)

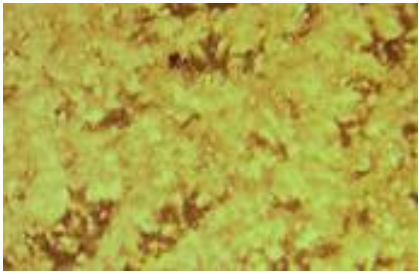

(d)

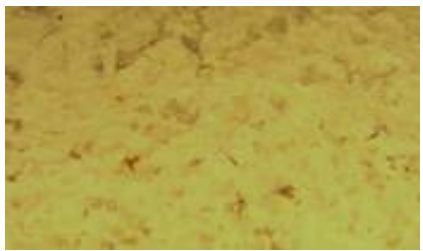

g)

Figure 1. Optical microscopy images for (a) achira starch-PVA (SP) films with different concentrations of MMT $(0.5,1.0$ and $1.5 \%)$, treated with (-s) and without sonication. 10x magnification. (a) SP, (b) SP0.5MMT, (c) SP1.0MMT, (d) SP1.5MMT, (e) SP0.5MMT-s, (f) SP1.0MMT-s and (g) SP1.5MMT-s

\subsection{Surface morphology by Scanning Electron Microscopy (SEM)}

Figure 2 presents micrographs to the films obtained surface, with and without sonication and different nanoclay contents. The control sample SP, shows a smooth, continuous and homogeneous surface, due to the interaction between hydroxyl groups of starch and PVA that promote stable formation of hydrogen bridges [27, 28]. In reference to the films reinforced with nanoclays, the formation of aggregates of MMT is observed, these are observed on the surface of the samples as undissolved particles. This effect is evident when the content of nanoclays increases, where the van der Waals forces favor that the nanometric particles hold together [29]. In the sonicated samples, the cavitation phenomenon facilitates the exfoliation of the sheets, reducing the size of their aggregates and promoting a better dispersion within the polymer matrix. 


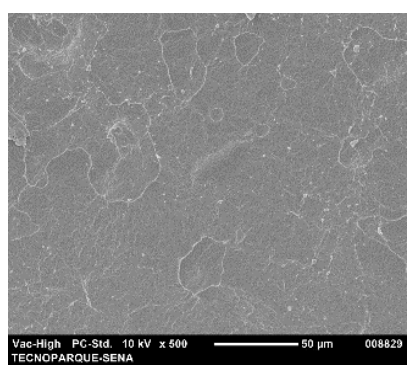

(a)

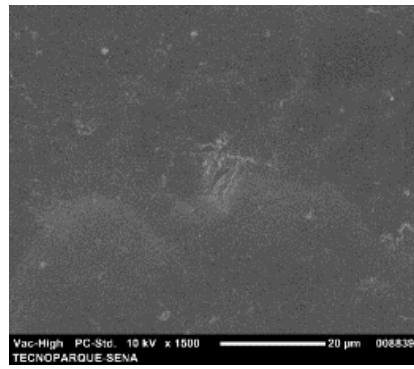

(b)

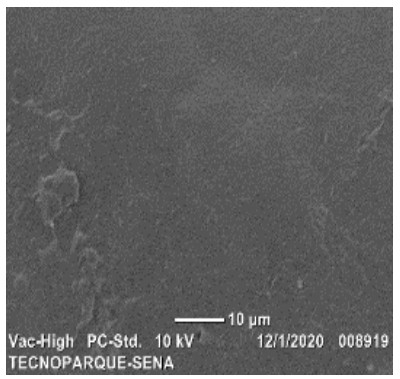

(e)

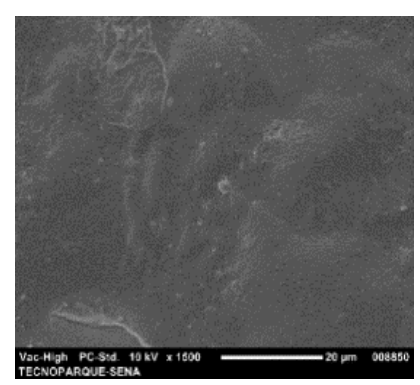

(c)

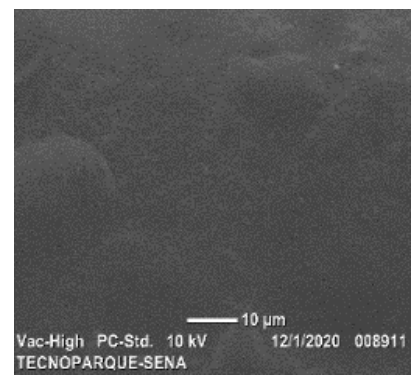

(f)

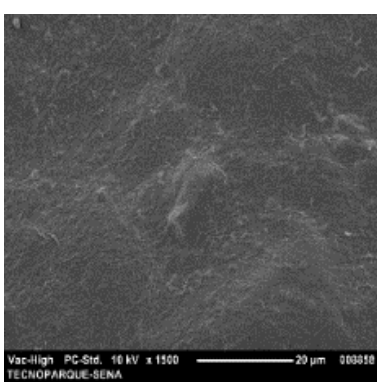

(d)

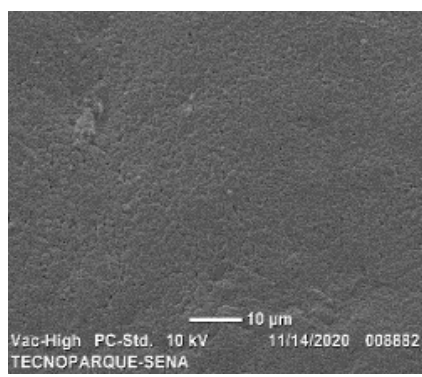

(g)

Figure 2. SEM micrographs for (a) achira starch-PVA (SP) biodegradable films with MMT nanoclay $(0.5,1.0$ and $1.5 \%)$, treated with (-s) and without sonication. 1500X magnification. (a) SP, (b) SP0.5MMT, (c) SP1.0MMT, (d) SP1.5MMT, (e) SP0.5MMT-s, (f) SP1.0MMT-s and (g) SP1.5MMT-s

\subsection{Opacity}

Table 1 shows the results of the optical properties related to translucency based on the integral over the maximum absorption peak values located for each mixture. In addition to the opacity values, the photos of each film (with $5 \mathrm{~cm}$ diameter) are presented. These values show increases directly proportional to the concentration of nanoclays. The behavior obtained is attributed to the fact that a higher load of nanoclays will increase the scattering of light and, therefore, affect the transmittance. However, the scattering minimizes the loss of transparency that can be seen with the naked eye. The sample SP1.5MMT, increased by 2.3 times compared to SP, sonication manages to decrease this relationship by 1.3. Appearance is a key factor for application in the packaging sector, in cases where applications are extending useful life products, increasing UV absorption capacity is beneficial. According to the results obtained by different authors, they justify that the opacity should not be significantly affected when there is good compatibility between the matrix and the nanoclay. When the clay plates that are well dispersed in the polymeric matrix have a small nanometric size, less than $1 \mathrm{~nm}$, they can allow the free passage of light without affecting the opacity of the materials [30]. 
Table 1. Opacity values and real images of appearance of the films to the human eye of polymeric bionanocomposite films.

\begin{tabular}{|c|c|c|c|c|c|}
\hline Sample & $\begin{array}{l}\text { Opacity } \\
(\mathrm{AU} \times \mathrm{nm})\end{array}$ & Pictures & Sample & $\begin{array}{l}\text { Opacity } \\
(\mathrm{AU} \times \mathrm{nm})\end{array}$ & Pictures \\
\hline SP & $\begin{array}{l}12.51 \pm 0.02 \mathrm{~A} \\
(\text { at } 400 \mathrm{~nm})^{*}\end{array}$ & & & & \\
\hline SP0.5MMT & $\begin{array}{l}12.96 \pm 0.09 \text { A,B } \\
(\text { at } 510 \mathrm{~nm})^{*}\end{array}$ & & SP0.5MMT-s & $\begin{array}{l}12.55 \pm 0.09 \text { A,B } \\
(\text { at } 510 \mathrm{~nm})^{*}\end{array}$ & \\
\hline SP1.0MMT & $\begin{array}{l}23.28 \pm 0.12 \text { a,c } \\
(\text { at } 590 \mathrm{~nm})^{*}\end{array}$ & & SP1.0MMT-s & $\begin{array}{l}15.26 \pm 0.08 \mathrm{a}, \mathrm{c} \\
(\text { at } 590 \mathrm{~nm})^{*}\end{array}$ & \\
\hline SP1.5MMT & $\begin{array}{l}28.87 \pm 0.17 \mathrm{a}, \mathrm{D} \\
(\text { at } 590 \mathrm{~nm})^{*}\end{array}$ & & SP1.5MMT-s & $\begin{array}{l}17.12 \pm 0.11^{\mathrm{a}, \mathrm{d}} \\
(\text { at } 590 \mathrm{~nm})^{*}\end{array}$ & \\
\hline
\end{tabular}

*Maximum absorption peak measured. a-d; A-D: Different letters in the same column denote significant differences for the set of means in each treatment (with and without ultrasound) $(\mathrm{p}<0.05$.

\subsection{FTIR-ATR Analysis}

In order to study the effects of the addition of nanoclays on the TPS/PVA matrix structure due to possible interactions between starch, PVA, glycerol, and bentonite clay the FT-IR analysis was performed (Figure 3). Bands located at 920, 996, 1026, 1073 and $1150 \mathrm{~cm}^{-1}$ are associated to C-O stretching, $1639 \mathrm{~cm}^{-1}$ is OH from bound water, $2938 \mathrm{~cm}-1$ is $\mathrm{C}-\mathrm{H}$ stretching, 3323 and $3450 \mathrm{~cm}^{-1}$ (-OH groups) and $1444 \mathrm{~cm}^{-1}$ assigned to the plasticizer glycerol, were observed. The band presented at $627 \mathrm{~cm}^{-1}$ can be attributed to the vibrations of the skeletal mode of the glucose rings. Some authors have reported similar results [31, 32]. The band located at $2889 \mathrm{~cm}^{-1}$ could be attributed to hydrogen bonding interactions between the hydroxyl groups of both biopolymers. On the other hand, MMT nanoclays present bands around $631 \mathrm{~cm}^{-1}$ and $1076 \mathrm{~cm}^{-1}$ attributed to the bending and stretching of Si-O-Si groups, respectively. These bans are related to the tetrahedral crystalline structure of the clay layers [33]. Likewise, bands are observed at 970 and $3615 \mathrm{~cm}^{-1}$ due to the vibration of the terminal silanol groups $(\mathrm{Si}-\mathrm{OH})$. The result of the strong interactions is evidenced between $920 \mathrm{~cm}^{-1}$ and $1120 \mathrm{~cm}^{-1}$ by means of the widening of the bands, due to the increase in the content of nanoclay. The interactions are related to the formation of hydrogen bridges, which limit the mobility of the $\mathrm{OH}$ groups, generating a decrease in the band around $3323 \mathrm{~cm}^{-1}$. 


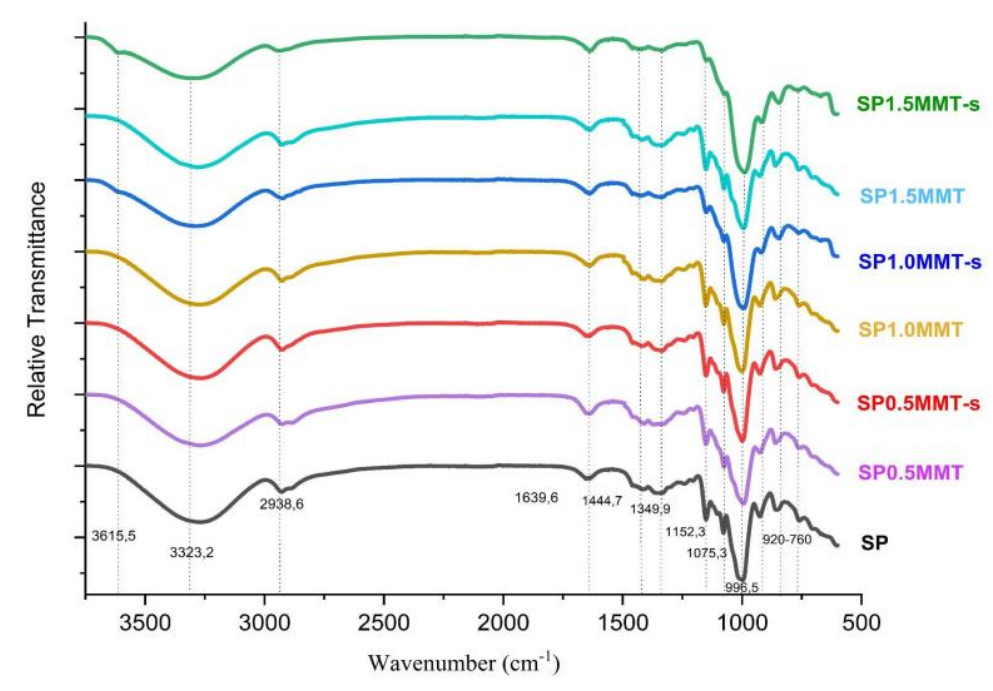

Figure 3. FT-IR spectra of bionanocomposite films at different concentrations of clay and ultrasound treatment.

\subsection{Thermal Analysis}

Figure 4 shows the curves obtained from the TGA analysis and their respective derivative for the polymeric bionanocompounds. Three thermal events can be observed. The first occurs in the range of $80{ }^{\circ} \mathrm{C}$ to $200{ }^{\circ} \mathrm{C}$, and refers to the evaporation of the water contained in the starch. The absorption of water by starch is high due to the hydrogen bonds formed by the hydroxyl groups (-OH) of glucose along its chain; these groups interact with the respective $\mathrm{OH}$ of water. The second stage corresponds to the evaporation of glycerol at temperatures between $200{ }^{\circ} \mathrm{C}$ and $280{ }^{\circ} \mathrm{C}$. Finally, in the third stage, the degradation of starch is observed, in this step the elimination of polyhydroxy groups, oxidative degradation of products from the previous step, and polymer fragmentation [7, 34]. Figure 4a shows an amplification between $30^{\circ} \mathrm{C}$ and $160^{\circ} \mathrm{C}$, this allows to determine the temperatures corresponding to weight losses of $10 \%$ (T10). It is evident that the T10 was increased for the bionanocomposites with ultrasound- assisted compared to the control film (SP), this trend was maintained for the other degradation temperatures. Figure $4 \mathrm{~b}$ shows a bifurcation in the maximum degradation band $\left(\sim 300^{\circ} \mathrm{C}\right)$ that relates the elimination of water of crystallization contained in the clay and the degradation of the polymeric matrix [35]. The crystallization water molecules were evidenced in the non-sonicated bionanocompounds, these samples are more prone to form agglomerates, due to the fact that the nanometric size of the clay has a high internal surface. In contrast, in the ultrasound-assisted mixing of the filmogenic solution, the sheets open due to the effect of cavitation, facilitating the dispersion and exfoliation process of the clay sheets, limiting the formation of agglomerates [36]. 


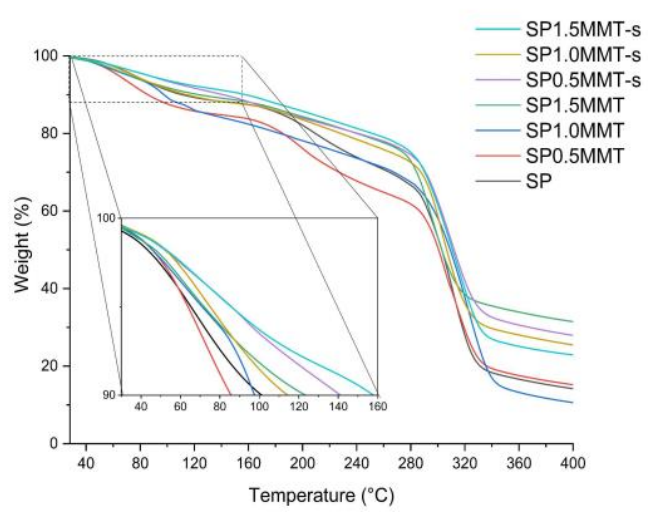

a)

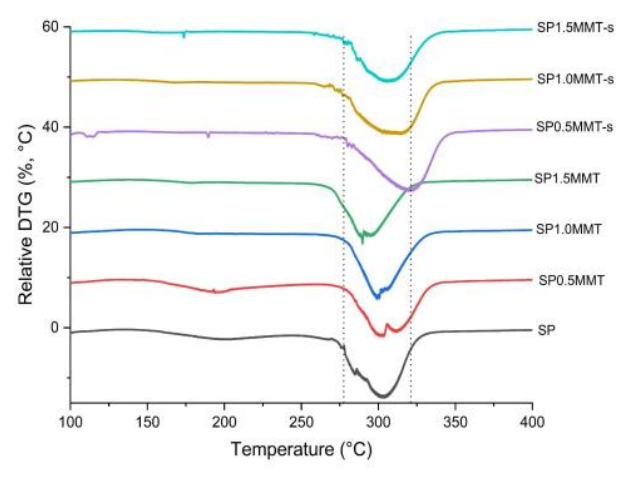

(b

Figure 4. Thermogravimetric Analysis (TGA) a) and Derivative Thermogravimetry (DTG) b) curves of bionanocomposite films at different concentrations of clay and ultrasound treatment.

The results of the thermal analysis are summarized in Table 2, in general, the nanocomposites without sonication showed a decomposition temperature close to that reported for the SP mixture with variations of $\sim 5^{\circ} \mathrm{C}$. On the other hand, the sonicated bionanocomposites showed increases of $10^{\circ} \mathrm{C}$ to $30^{\circ} \mathrm{C}$, for SP0.5MMT-s and SP1.0MMT-s, respectively. The thermal resistance that the incorporation of nanoclays promotes in polymeric materials has been widely reported [37]. However, the quality of the dispersion process of the clay sheets on the matrix must be guaranteed. This will induce an increase in the surface area of the particles that allow greater interaction. The results obtained in the infrared are directly related to showing stronger interactions of TPS/PVA with montmorillonite, this explains why the structure of starch is reorganized with less exposed hydroxyl groups, thus reducing the susceptibility to degradation by heat [20].

Table 2. Weight losses of $10 \%\left(\mathrm{~T}_{10}\right)$, initial degradation $\left(\mathrm{T}_{\mathrm{i}}\right)$, maximum degradation $\left(\mathrm{T}_{\mathrm{d}}\right)$, final degradation $\left(\mathrm{T}_{\mathrm{f}}\right)$, glass transition $\left(\mathrm{T}_{\mathrm{g}}\right)$ and melting $\left(\mathrm{T}_{\mathrm{m}}\right)$ temperatures, results based on the obtained TGA and DSC thermograms for the bionanocomposites.

\begin{tabular}{cccccccc}
\hline \multirow{2}{*}{ Sample } & $\mathbf{T}_{\mathbf{1 0}}$ & $\mathbf{T}_{\mathbf{i}}$ & $\mathbf{T}_{\mathbf{d}}$ & $\mathbf{T}_{\mathbf{f}}$ & $\mathbf{T}_{\text {gel }}$ & $\mathbf{T}_{\mathbf{m}}$ (TPS) & $\mathbf{T}_{\mathbf{g}}$ (PVA) \\
\cline { 2 - 8 } & & & \multicolumn{7}{c}{$\left({ }^{\circ} \mathrm{C}\right)$} \\
\hline SP & 105.0 & 264.4 & 297.3 & 329.5 & 77.8 & -- & -- \\
\hline SP0.5MMT & 85.3 & 271.7 & 300.3 & 336.1 & 74.5 & -- & 196.6 \\
\hline SP1.0MMT & 97.2 & 268.8 & 295.9 & 335.5 & 81.1 & -- & 184.8 \\
\hline SP1.5MMT & 122.5 & 268.1 & 292.3 & 334.7 & 82.6 & -- & 203.0 \\
\hline SP0.5MMT-s & 140.6 & 269.5 & 306.2 & 342.8 & 98.1 & 116.4 & 191.3 \\
\hline SP1.0MMT-s & 113.0 & 271.2 & 327.7 & 353.7 & 96.0 & -- & 182.8 \\
\hline SP1.5MMT-s & 156.8 & 279.0 & 312.7 & 346.4 & 96.1 & -- & 170.9 \\
\hline
\end{tabular}

Figure 5 presents the DSC curves of the polymeric bionanocomposite films, where the first order and second-order transition temperatures are observed, related to the melting of each polymer $\left(\mathrm{T}_{\mathrm{m}}\right)$, gelatinization of the starch $\left(\mathrm{T}_{\mathrm{gel}}\right)$, and the glass transition of the PVA $\left(\mathrm{T}_{\mathrm{g}}\right)$, respectively. Second-order transitions appear as a large band between $35^{\circ} \mathrm{C}$ and $98^{\circ} \mathrm{C}$, this broadening is due to the superposition of the $\mathrm{T}_{\mathrm{g}}$ and $\mathrm{T}_{\text {gel }}$ indicated in Table 3 .

$\mathrm{T}_{\text {gel }}$ of starch and non-sonicated nanocomposites is observed with greater definition between $74{ }^{\circ} \mathrm{C}$ and $82{ }^{\circ} \mathrm{C}$, where probably the gelatinization of some granules was not completed. While the ultrasound-assisted samples increased by more than $10{ }^{\circ} \mathrm{C}$ in this 
transition, the band appears less intense. This indication shows that the ultrasound radiation on the solution promotes gelatinization. The peak presented at $116^{\circ} \mathrm{C}$ corresponded to the melting temperature of the SP0.5MMT-s film, showing a higher degree of molecular ordering for this material compared to the other blends. The displacement of the peak indicates a strong interaction with the clay with the polymers, especially with the starch, generating a thermal insulating effect. These results are consistent with chitosan/PVA systems obtained by Giannakas et al. [38]. A synergistic effect is shown that relates the clay content and sonication with the variables $\mathrm{T}_{\text {gel }}$ with $\mathrm{T}_{\mathrm{g}}(\mathrm{PVA})$. On the other hand, the fusion of PVA was evidenced around $180^{\circ} \mathrm{C}$, this transition did not present a clear trend.

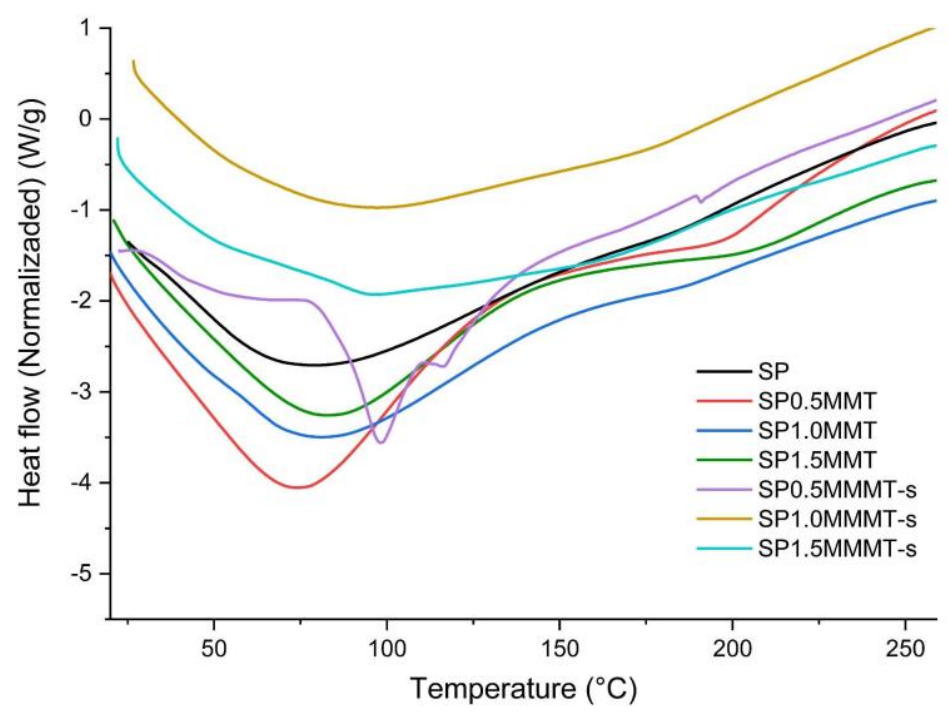

Figure 5. DSC thermograms of bionanocomposite films at different concentrations of clay and ultrasound treatment.

\subsection{Contact Angle and Water Absorption}

The wettability and the absorbent properties of films were studied across the contact angle and water absorption, respectively. The results of these analyses are shown in Figure 6. In both parameters, the modifications due to the incorporation of MMT nanoclay was possible to observe. However, the sonication of MMT nanoclay is a key understanding that the properties can be improved; due to the films with MMT nanoclay sonicated showed a better wettability and absorbent properties. The highest values of contact angle with respect to SP were presented by SP1.0MMT-s with an increase of almost 50\%, thus reducing the hydrophilicity of the material. This can be explained by the possible ion-dipole interactions between the nanoclay with the $\mathrm{OH}$ groups of starch, water and glycerol, given the low availability of hydroxyl groups, the instantaneous interaction (<30 seconds) with water may possibly decrease in part of the SP/PVA matrix [39] causing better droplet conformation. However, to achieve this type of interaction, the influence of ultrasound is required so that the silicate can be uniformly dispersed on the polymer matrix. The significant increase that SP0.5MMT had in the contact angle can be attributed to the formation of an aggregate on the surface; this could be confirmed through the obtained micrographs.

On the other hand, the effect of increase of the water absorption in the films with nanoclay without sonication could be attributed to the interlaminar space of the nanoclay, this increase in spatial separation was observed as higher swelling (Figure 6b). This process depends on the balance between the cation-sheet electrostatic attraction and the hydration energy of the cation. When sodium is the interlaminar cation, smectics have a high swelling capacity, and a complete dissociation of individual smectite crystals can occur, resulting in a high degree of dispersion and maximum development of colloidal properties [40]. 


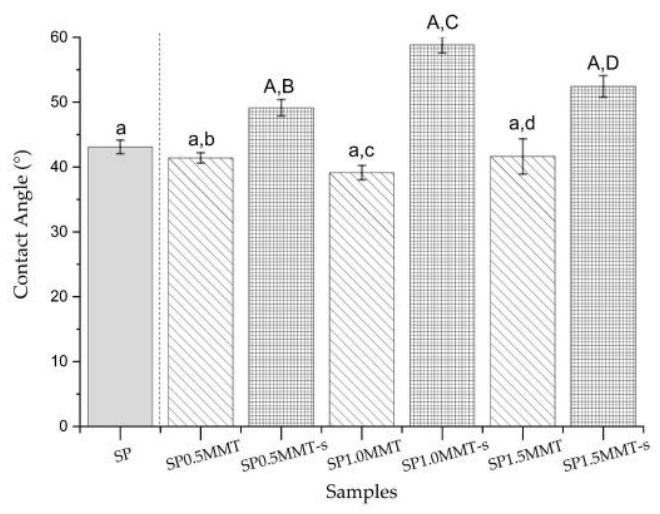

a)

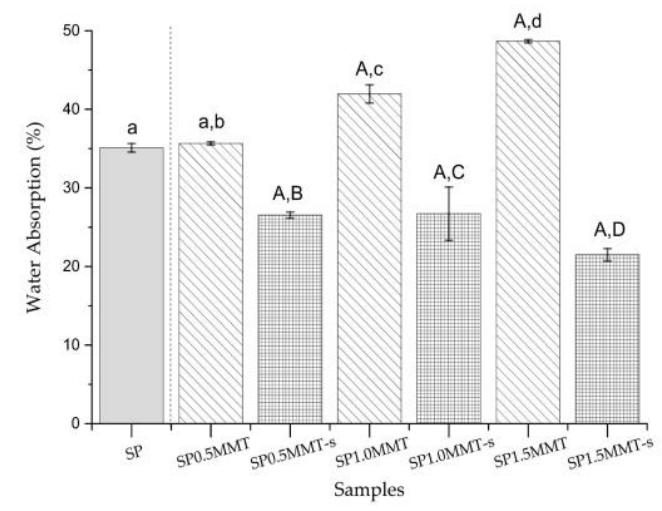

b)

Figure 6. Effect of MMT nanoclay concentration and ultrasound treatment on a) contact angle and b) water absorption of SP/PVA composite films. a-d; A-D: Different letters in the same type of bar design denotes significant differences for the set of means in each treatment (with and without ultrasound) $(\mathrm{p}<0.05)$

\subsection{Water Vapor Permeability (WVP)}

The evaluation of the materials to determine their water vapor barrier capacity indicated that the nanostructure of the SP/PVA films reinforced with the MMT nanoclay creates a more tortuous path for the passage of the permeant gas. The water vapor molecules that penetrate through the film diffuse, taking the path of least resistance, often opting for the longer channels between the layers that make up the clay rather than the openings between the clay platelets arranged in thickness direction, that is, the gas molecules travel perpendicular to the diffusion direction, thus creating a longer and more complicated path, significantly reducing the gas transmission rate that is reflected in lower values of water vapor transmission rate (Table 3). However, although the WVTR was lower in the films with clay compared to those lacking this nanofiller (SP), the WVTR reduction effect was more noticeable in the films with the lowest clay content (SP0.5MMT-s). It was observed that in the polymeric SP/PVA formulations, an addition greater than $0.5 \%$ of MMT causes a significant increase in the WVTR, which is also reflected as a decrease in the barrier capacity of the materials.

Despite the fact that films with a different proportion of nanoclay adsorbed similar amounts of water (Figure 6b), this behavior does not seem to influence the gas barrier behavior of the material in the same way. Even though the water adsorption was lower in the film formulated with 1.5MMT, both the WVTR and the WVP of this material was much higher than that of the materials with the lowest clay content (0.5). Which is an indication that these nano-reinforcements are interacting differently in the structural matrix of each of the formulated films.

This effect of improvement in the barrier capacity of the materials at low concentrations of nanoclay may be due to a better dispersion and structural accommodation of the clay sheets in the polymeric matrix. Whereas when the concentration of MMT is higher, it becomes an excess, it acts as an intermolecular free space increasing agent, which is why an adequate arrangement and more compact arrangement of other sheets in the matrix of the composite polymer is no longer possible, facilitating the passage of gases increasing their permeation. 
Table 3. Water vapor transmission rate (WVTR) and water vapor permeability (WVP) of starch-polyvinyl alcohol (SP) film reinforced with nanoclays (MMT), sonicated with ultrasound.

\begin{tabular}{ccc}
\hline Film sample & $\begin{array}{c}\text { WVTR } \\
\text { g.mm } /\left(\mathrm{m}^{2 *} \text { day }\right)\end{array}$ & $\begin{array}{c}\text { WVP } \\
\mathrm{g} /\left(\mathrm{m}^{2 *} \text { day }\right)\end{array}$ \\
\hline SP & 1073.2170 & 4658.290 \\
\hline SP0.5MMT-s & 331.3667 & 3122.959 \\
\hline SP1.0MMT-s & 736.2055 & 3675.283 \\
\hline SP1.5MMT-s & 884.4438 & 4836.468 \\
\hline
\end{tabular}

\subsection{Mechanical properties}

Table 4 presents the results of the tensile tests that were done to the sonicated samples and the control sample, for tensile strength (TS), percentage of elongation at break $(\varepsilon)$ and Young's modulus (YM). As has been reported by other authors [4, 5, 14, 19, 29], the addition of nanoclay increased the TS and YM for all nanoclay concentrations compared to the values obtained by the SP sample, where the greatest increase is presented by SP1.0MMTs (24\% tensile strength and 50\% Young's modulus). The nanometric size of the clays and their high surface area, favor the formation of an effective interface to transfer tensile stresses. In addition, the presence of nanoclay with higher rigidity can limit the macromolecular mobility of the polymeric matrix, generating an increase in the elastic modulus of the nanocomposite films [41]. These same results were found by Tin et al. [42] by showing that both mechanical properties were increased by the presence of MMT in blends of PVA/starch with 0 to $25 \%$ of MMT. However, as has been demonstrated by SEM, higher nanoclay contents favor the formation of aggregates, which leads to a deterioration in these properties in the SP1.5MMT-s sample.

The SP0.5MMT-s sample presents a 35\% increase in $\varepsilon$, compared to the SP sample, since the interaction of starch with the crystallization water molecules contained in the nanoclay generates a plasticizing effect that increases its elongation capacity. In the other hand, the addition of a higher content of nanoclays did not significantly modify this property in the films SP1,0MMT-s and SP1,5MMT-s, Due to the fact that the addition of a higher quantity of nanoclay favors the formation of new nucleation points that contribute to the growth of the polymer crystals, causing more fragile films. These is consistent with the result obtained by Müller et al., who developed TPS nanocomposites with two types of nanoclay and two different concentrations, where, the control presents a maximum elongation of $63 \pm 12 \%$, while when including the nanoclays the values are between 74 and $76 \%$, evidencing in all cases the low incidence on $\varepsilon$ [4].

Table 4. Mechanical properties of TPS films reinforced with nanoclays.

\begin{tabular}{cccc}
\hline Sample & TS $(\mathrm{MPa})$ & $\varepsilon(\%)$ & $Y M(\mathrm{MPa})$ \\
\hline SP & $3.73 \pm 0.30^{\mathrm{a}}$ & $39.45 \pm 10.9^{\mathrm{a}}$ & $0.179 \pm 0.01^{\mathrm{a}}$ \\
\hline SP0.5MMT-s & $3.87 \pm 0.32^{\mathrm{a}}$ & $61.39 \pm 9.6^{\mathrm{b}}$ & $0.138 \pm 0.02^{\mathrm{a}}$ \\
\hline SP1.0MMT-s & $4.89 \pm 0.37{ }^{\mathrm{b}}$ & $33.16 \pm 7.3^{\mathrm{a}}$ & $0.360 \pm 0.05^{\mathrm{b}}$ \\
\hline SP1.5MMT-s & $4.75 \pm 0.25^{\mathrm{b}}$ & $34.54 \pm 4.2^{\mathrm{a}}$ & $0.328 \pm 0.03^{\mathrm{b}}$ \\
\hline
\end{tabular}

TS: tensile strength, $\varepsilon$ : elongation at break, YM: Young's modulus $a-b$ Different letters in the same column indicate significant differences $(p<0.05)$. Mean of five replications \pm standard deviation. 


\section{Materials and Methods}

\subsection{Materials}

The following biopolymers were used: Achira starch by Surtialmidon (Huila, Colombia) with a density of $1.59 \mathrm{~g} / \mathrm{mL}$; Polyvinyl alcohol (PVA) from Fluka Analytica (Prague, The Czech Republic) (Mw =47,000 g/mol), with a polymerization degree of 1000 and 98\% of hydrolysis. Montmorillonite nanoclay (MMT), hydrophilic bentonite density of 600 $1100 \mathrm{~kg} / \mathrm{m} 3$, average particle size $\leq 25 \mu \mathrm{m}$ by Sigma-Aldrich (St. Louis, MO, USA) and Glycerol with a density of $1.26 \mathrm{~g} / \mathrm{mL}$ (purity: $99.68 \%$ ).

\subsection{Film Preparation}

In this study, the formulation and methodology proposed by Gómez-Aldapa et al. (2020) was followed for the production of biodegradable films. The PVA solution was prepared by dissolving the PVA in distilled water at a concentration of $4 \%(\mathrm{w} / \mathrm{v})$ and heated to $70{ }^{\circ} \mathrm{C}$ and kept at that temperature under stirring for 2 hours. For the nanocomposite films of starch-PVA-nanoclay, the corresponding glycerol $(25 \% \mathrm{w} / \mathrm{w}$, total polymers) was first added in distilled water and stirred for $5 \mathrm{~min}$. Once the plasticizer had dissolved, the achira starch was added and stirred until a temperature of $50{ }^{\circ} \mathrm{C}$ was reached. After the temperature was reached, the corresponding PVA solution was incorporated, and the nanoclay dispersed in water was added. The solution was kept under stirring and the temperature was raised to $85^{\circ} \mathrm{C}$ to gelatinize the starch for 5 minutes. The filmogenic solution was treated with an ultrasonic water bath (Elmasonic Easy $120 \mathrm{H}$, Elma Schmidbauer $\mathrm{GmbH}$, Singen, Germany, at a fixed frequency of $37 \mathrm{kHz}$ and power of $200 \mathrm{~W}$ ) for $5 \mathrm{~min}$ at $85{ }^{\circ} \mathrm{C}$ to favor the dispersion of the nanoparticles. The filmogenic solution obtained was poured into Petri dish covered by a Teflon sheet and subsequently drying it in a humidity chamber at $65^{\circ} \mathrm{C}$ and $50 \mathrm{RH} \%$ for $5 \mathrm{~h}$. Thickness of the films was $180 \pm 20 \mu \mathrm{m}$. Prior to the analysis, the films were stored at $25^{\circ} \mathrm{C}$ and $50 \% \mathrm{RH}$.

Table 5. Contains the list of blends, their composition applied for their preparation.

\begin{tabular}{lcccc}
\hline \multicolumn{1}{c}{ Sample* } & Starch $(\%)$ & PVA $(\%)$ & Nanoclay $(\%)$ & Mixing method \\
\hline SP (control) & 60 & 40 & 0 & Stir \\
\hline SP0.5MMT & 60 & 40 & 0.5 & Stir \\
\hline SP1.0MMT & 60 & 40 & 1.0 & Stir \\
\hline SP1.5MMT & 60 & 40 & 1.5 & Stir \\
\hline SP0.5MMT-s & 60 & 40 & 0.5 & Stir and sonication \\
\hline SP1.0MMT-s & 60 & 40 & 1.0 & Stir and sonication \\
\hline SP1.5MMT-s & 60 & 40 & 1.5 & Stir and Sonication \\
\hline
\end{tabular}

${ }^{*}$ Abbreviation: Thermoplastic Starch $=$ S, Polyvinyl alcohol = P, Montmorillonite nanoclay $=$ MMT and sonication $=\mathrm{s}$.

\subsection{Characterization}

\subsubsection{Optical Microscopy}

In order to determine the surface morphology of films at low magnification, the optical microscopy was used with an Olympus BX60 light microscope (Tokyo, Japan) at 10x magnification, the films were dried at room temperature and immobilized on a glass slide.

\subsubsection{Scanning Electron Microscopy}

The surface of the films was analyzed at great magnification using a JEOL, JCM 50,000 (Tokyo, Japan) scanning electron microscope (SEM). A voltage of $10 \mathrm{kV}$ was applied. The samples were covered with a gold layer. The surface films were analysed at 1500X and 3000X. 


\subsubsection{Opacity}

The opacity of the films was determined using the methodology proposed by Mali and Grossmann [43]. Composite films were cut at $1 \times 3 \mathrm{~cm}$ and placed inside a Shuimadzu UV-VIS 2600 spectrophotometer cell, samples were measured between 400-800 nm. The opacity was defined as the area under the curve and was defined as absorbance units $\mathrm{x}$ nanometers (AU nm). Measurements were done in duplicate.

\subsubsection{Fourier Transformed Infrared Spectroscopy (FT-IR)}

FT-IR analysis of films was carried out by ATR mode using a spectrophotometer Spectrum 3 by PerkinElmer. Dry films were analysed by 16 scans, a wave number range between 600 and $4000 \mathrm{~cm}^{-1}$ and a $4 \mathrm{~cm}^{-1}$ resolution.

\subsubsection{Thermal properties}

Thermal stability of films was determined by thermogravimetric analysis (TGA) using a TGA/DSC 2 STAR System instrument, Mettler Toledo, USA. The sample was heated from $25^{\circ} \mathrm{C}$ to $600{ }^{\circ} \mathrm{C}$ at a heating rate of $20^{\circ} \mathrm{C} / \mathrm{min}$ under a nitrogen purge at a flow rate of $60 \mathrm{~mL} / \mathrm{min}$. The weight loss was shown as a function of temperature.

In order to identify the thermal transitions of films the Differential Scanning Calorimetry (DSC) was carried out with a TA Q-2000 equipment at a heating rate of $10^{\circ} \mathrm{C} / \mathrm{min}$ in a temperature range from 25 to $200^{\circ} \mathrm{C}$ with a nitrogen purge.

\subsubsection{Contact Angle}

The contact angle was measured using a goniometer Ramé-Hart Model 250 at room temperature. A drop of distilled water $(20 \mu \mathrm{l})$ was dropped onto the surface of the sample before measuring the contact angle of the water as a function of time. The measurement was done by triplicate. The statistical analysis was done by variance (ANOVA) with a significance level of 0.05 .

\subsubsection{Water Absorption}

To study the water absorption behavior of the films, they were cut to size of $2 \times 2 \mathrm{~cm}$ and dried for 4 hours at $50^{\circ} \mathrm{C}$, later; films were weighed and soaked in distilled water for 6 hours at room temperature, subsequently, the weight of the drained films was taken. The water absorption was calculated with the equation (1):

$$
\% W=\frac{W_{t}-W_{0}}{W_{0}} \times 100
$$

Where $W_{t}$ is the weight of films after the exposed time interval and $W_{0}$ is the initial dry weight of the sample.

\subsubsection{Water vapor transmission rate (WVTR) and Water vapor permeability (WVP)}

The water vapor transmission rate (WVTR) was performed at a Permatran 3/33 apparatus (Mocon Inc., Minneapolis, USA). The test conditions were: film sample area of 5 $\mathrm{cm}^{2} 25^{\circ} \mathrm{C}, 50 \% \mathrm{RH}$, and the partial pressure of oxygen was $760 \mathrm{mmHg}$. To determine the WVP, the WVTR was normalized to the film thickness $(180 \mu \mathrm{m})$. Three replicates for each film formulation were made, and the mean value was reported. This determination was only carried out on films obtained from filmogenic solutions treated with sonication.

\subsubsection{Tensile Test}

The mechanical properties were measured by a tensile test, which was done with a universal machine INSTRON model EMIC 23-50, equipped with a $50 \mathrm{kN}$ load. The measurements were done on 6 specimens for each sample with dimensions of $10 \times 2.5 \mathrm{~cm}$ and a thickness variable, using a constant rate of $1 \mathrm{~cm} / \mathrm{min}$ until rupture. The samples were conditioned previously at $23^{\circ} \mathrm{C}$ for 2 days. This characterization was only performed on materials obtained from sonicated film-forming solutions like the WVP test. 


\subsection{Statistical Analysis}

Analysis of variance (ANOVA) was performed by Tukey's test (0.05 level of significance) to compare mean differences of the nanocomposite films formulations. All statistical analyzes were performed with IBM SPSS Statistics 25.

\section{Conclusions}

In this work, bionanocomposite films based on the TPS/PVA blend by varying MMT nanoclay content of $0.5-1.5 \%$ and are treated in the presence of ultrasound using sol-ventcasting method. It has been found that nanofillers are preferentially located into TPS matrix due to the polar interaction between the silicate layers of montmorillonite and TPS, they also interact with the polar groups of PVA. Platelets are more effective when processed in the presence of ultrasound because of the strong interactions between the biopolymeric blend matrix and clay nanoparticles, as verified by FT-IR and SEM analyses. The use of an ultrasound treatment generated materials with a better, more homogeneous surface, as observed with the SEM, as well as a reduction in the water susceptibility of the films by contact angle and water absorption. The thermal properties of the nanocomposite biomaterials revealed an improvement in thermal stability compared to the biopolymer mixture (SP) due to the insulating effect of the nanoclays present. Strong intermolecular interactions were evidenced in the ultrasound-treated samples, observed as thermal transitions at higher temperatures. Furthermore, the SP0.5MMT-s film showed complete plasticization concerning the SP control and its non-sonicated counterpart (SP0.5MMT). The incorporation of the MMT nanoclay had a reinforcing effect, causing an improvement in the tensile stress mechanical properties and Young's modulus of the TPS film. Likewise, it is possible to obtain composite materials reinforced with MMT with different water vapor barrier behaviors, which can be achieved by increasing the concentration of the nanoclay. At low concentrations of MMT, a less gas-permeable material is obtained, but when the percentage is 1.0 or higher, the material becomes more permeable.

These results demonstrate that nanoclays are promising nanoreinforcers to improve the functional properties of packaging materials made from TPS/PVA blends and constitute a new sustainable material for potential application in the packaging sector. Combining these new approaches provides the necessary innovation capable of potentiating the migration towards more sustainable materials with shorter degradation times and the required performance characteristics for their application in different industrial sectors.

\section{Patents}

Author Contributions: Conceptualization, C.C. and R.Y.A.-L; methodology, C.C., H.L.C., R.Y.A.L., A.F.-G. and D.A.; formal analysis, C.C., H.L.C., R.Y.A.-L., A.F.-G. and D.A.; investigation, C.C., H.L.C. and D.A.; visualization, C.C., H.L.C. and D.A.; supervision, C.C. and R.Y.A.-L.; project administration, C.C. and H.L.C.; writing-original draft preparation, H.L.C., A.F.-G., R.Y.A.-L. and C.C.; writing - review and editing, H.L.C., A.F.-G., R.Y.A.-L. and C.C. All authors have read and agreed to the published version of the manuscript.

Funding: This research has been funded by Dirección General de Investigaciones (DGI) of Universidad Santiago de Cali under call No. 01-2021. C.C. Acknowledge financial support from DGI of Universidad Santiago de Cali under project No. 939-621120-2148; and by Centro de Investigación en Química Aplicada (CIQA) under internal project 6610 (2021).

Data Availability Statement: The data are available on request from the corresponding author.

Acknowledgments: The authors gratefully acknowledge the ASTIN-SENA, Research Group in Development of Materials and Products (GIDEMP by its Spanish acronym), Bio- and Nano-technology line of Tecnoparque in 2020-2021. Also, we thank the SENNOVA (ASTIN code OT- PI 0023-18). The authors Fonseca-García and Aguirre-Loredo thank CONACYT for their nominations as researchers assigned to CIQA.

Conflicts of Interest: The authors declare no conflict of interest.

Sample Availability: Samples of the compounds ... are available from the authors. 


\section{References}

1. Palai, B.; Biswal, M.; Mohanty, S.; Nayak, S. K., In situ reactive compatibilization of polylactic acid (PLA) and thermoplastic starch (TPS) blends; synthesis and evaluation of extrusion blown films thereof. Industrial Crops and Products 2019, 141, 111748.

2. Przybytek, A.; Sienkiewicz, M.; Kucińska-Lipka, J.; Janik, H., Preparation and characterization of biodegradable and compostable PLA/TPS/ESO compositions. Industrial Crops and Products 2018, 122, 375-383.

3. Ranganathan, S.; Dutta, S.; Moses, J.; Anandharamakrishnan, C., Utilization of food waste streams for the production of biopolymers. Heliyon 2020, 6, (9), e04891.

4. Müller, C. M.; Laurindo, J. B.; Yamashita, F., Composites of thermoplastic starch and nanoclays produced by extrusion and thermopressing. Carbohydrate polymers 2012, 89, (2), 504-510.

5. Ayana, B.; Suin, S.; Khatua, B., Highly exfoliated eco-friendly thermoplastic starch (TPS)/poly (lactic acid)(PLA)/clay nanocomposites using unmodified nanoclay. Carbohydrate polymers 2014, 110, 430-439.

6. Caicedo, C.; Pulgarin, H. L. C., Study of the Physical and Mechanical Properties of Thermoplastic Starch/Poly (Lactic Acid) Blends Modified with Acid Agents. Processes 2021, 9, (4), 578.

7. Gómez-Aldapa, C. A.; Velazquez, G.; Gutierrez, M. C.; Rangel-Vargas, E.; Castro-Rosas, J.; Aguirre-Loredo, R. Y., Effect of polyvinyl alcohol on the physicochemical properties of biodegradable starch films. Materials Chemistry and Physics 2020, 239, 122027.

8. Cano, A. I.; Cháfer, M.; Chiralt, A.; González-Martínez, C., Physical and microstructural properties of biodegradable films based on pea starch and PVA. Journal of Food Engineering 2015, 167, 59-64.

9. Butron, A.; Llorente, O.; Fernandez, J.; Meaurio, E.; Sarasua, J.-R., Morphology and mechanical properties of poly(ethylene brassylate)/cellulose nanocrystal composites. Carbohydrate Polymers 2019, 221, 137-145.

10. Ren, J.; Dang, K. M.; Pollet, E.; Avérous, L., Preparation and characterization of thermoplastic potato starch/halloysite nanobiocomposites: effect of plasticizer nature and nanoclay content. Polymers 2018, 10, (8), 808.

11. Kwaśniewska, A.; Świetlicki, M.; Prószyński, A.; Gładyszewski, G., The Quantitative Nanomechanical Mapping of Starch/Kaolin Film Surfaces by Peak Force AFM. Polymers 2021, 13, (2), 244.

12. Kwaśniewska, A.; Chocyk, D.; Gładyszewski, G.; Borc, J.; Świetlicki, M.; Gładyszewska, B., The influence of kaolin clay on the mechanical properties and structure of thermoplastic starch films. Polymers 2020, 12, (1), 73.

13. Gaaz, T. S.; Sulong, A. B.; Akhtar, M. N.; Kadhum, A. A. H.; Mohamad, A. B.; Al-Amiery, A. A., Properties and applications of polyvinyl alcohol, halloysite nanotubes and their nanocomposites. Molecules 2015, 20, (12), 22833-22847.

14. Müller, C. M.; Laurindo, J. B.; Yamashita, F., Effect of nanoclay incorporation method on mechanical and water vapor barrier properties of starch-based films. Industrial Crops and Products 2011, 33, (3), 605-610.

15. Majdzadeh-Ardakani, K.; Nazari, B., Improving the mechanical properties of thermoplastic starch/poly (vinyl alcohol)/clay nanocomposites. Composites Science and Technology 2010, 70, (10), 1557-1563.

16. Wang, W.; Zhang, H.; Jia, R.; Dai, Y.; Dong, H.; Hou, H.; Guo, Q., High performance extrusion blown starch/polyvinyl alcohol/clay nanocomposite films. Food Hydrocolloids 2018, 79, 534-543.

17. Dean, K. M.; Do, M. D.; Petinakis, E.; Yu, L., Key interactions in biodegradable thermoplastic starch/poly (vinyl alcohol)/montmorillonite micro-and nanocomposites. Composites Science and Technology 2008, 68, (6), 1453-1462.

18. Gao, W.; Dong, H.; Hou, H.; Zhang, H., Effects of clays with various hydrophilicities on properties of starch-clay nanocomposites by film blowing. Carbohydrate polymers 2012, 88, (1), 321-328.

19. Sorrentino, A.; Gorrasi, G.; Vittoria, V., Potential perspectives of bio-nanocomposites for food packaging applications. Trends in food science $\mathcal{E}$ technology 2007, 18, (2), 84-95.

20. Wilhelm, H.-M.; Sierakowski, M.-R.; Souza, G.; Wypych, F., Starch films reinforced with mineral clay. Carbohydrate Polymers 2003, 52, (2), 101-110. 
21. Romero-Bastida, C. A.; Chávez Gutiérrez, M.; Bello-Pérez, L. A.; Abarca-Ramírez, E.; Velazquez, G.; Mendez-Montealvo, G., Rheological properties of nanocomposite-forming solutions and film based on montmorillonite and corn starch with different amylose content. Carbohydrate Polymers 2018, 188, 121-127.

Chivrac, F.; Pollet, E.; Dole, P.; Avérous, L., Starch-based nano-biocomposites: Plasticizer impact on the montmorillonite exfoliation process. Carbohydrate Polymers 2010, 79, (4), 941-947.

23. Schlemmer, D.; Angélica, R. S.; Sales, M. J. A., Morphological and thermomechanical characterization of thermoplastic starch/montmorillonite nanocomposites. Composite Structures 2010, 92, (9), 2066-2070.

24. Kampeerapappun, P.; Aht-ong, D.; Pentrakoon, D.; Srikulkit, K., Preparation of cassava starch/montmorillonite composite film. Carbohydrate Polymers 2007, 67, (2), 155-163.

25. Müller, P.; Kapin, É.; Fekete, E., Effects of preparation methods on the structure and mechanical properties of wet conditioned starch/montmorillonite nanocomposite films. Carbohydrate polymers 2014, 113, 569-576.

26. Shayan, M.; Azizi, H.; Ghasemi, I. a.; Karrabi, M., Effect of modified starch and nanoclay particles on biodegradability and mechanical properties of cross-linked poly lactic acid. Carbohydrate polymers 2015, 124, 237-244.

Guimarães Jr, M.; Botaro, V. R.; Novack, K. M.; Teixeira, F. G.; Tonoli, G. H. D., Starch/PVA-based nanocomposites reinforced with bamboo nanofibrils. Industrial Crops and Products 2015, 70, 72-83.

Sin, L. T.; Rahman, W.; Rahmat, A.; Khan, M., Detection of synergistic interactions of polyvinyl alcohol-cassava starch blends through DSC. Carbohydrate Polymers 2010, 79, (1), 224-226.

29. Majdzadeh-Ardakani, K.; Navarchian, A. H.; Sadeghi, F., Optimization of mechanical properties of thermoplastic starch/clay nanocomposites. Carbohydrate Polymers 2010, 79, (3), 547-554.

30. Liu, G.; Song, Y.; Wang, J.; Zhuang, H.; Ma, L.; Li, C.; Liu, Y.; Zhang, J., Effects of nanoclay type on the physical and antimicrobial properties of PVOH-based nanocomposite films. LWT-Food Science and Technology 2014, 57, (2), 562-568.

31. Kizil, R.; Irudayaraj, J.; Seetharaman, K., Characterization of irradiated starches by using FT-Raman and FTIR spectroscopy. Journal of agricultural and food chemistry 2002, 50, (14), 3912-3918.

Zhang, Y.; Han, J., Mechanical and thermal characteristics of pea starch films plasticized with monosaccharides and polyols. Journal of Food Science 2006, 71, (2), E109-E118.

33. Yilmaz, O.; Cheaburu, C.; Durraccio, D.; Gulumser, G.; Vasile, C., Preparation of stable acrylate/montmorillonite nanocomposite latex via in situ batch emulsion polymerization: effect of clay types. Applied clay science 2010, 49, (3), $288-297$.

34. Liu, Y.; Wang, S.; Lan, W., Fabrication of antibacterial chitosan-PVA blended film using electrospray technique for food packaging applications. International journal of biological macromolecules 2018, 107, 848-854.

35. García-López, D.; Fernández, J. F.; Merino, J. C.; Santarén, J.; Pastor, J. M., Effect of organic modification of sepiolite for PA 6 polymer/organoclay nanocomposites. Composites Science and Technology 2010, 70, (10), 1429-1436.

36. Sanchez-Olivares, G.; Calderas, F.; Sanchez-Solis, A.; Medina-Torres, L.; Moreno, L. R.; Manero, O., Assessment of extrusionsonication process on flame retardant polypropylene by rheological characterization. AIMS Materials Science 2016, 3, (2), 620-633.

Sessini, V.; Arrieta, M. P.; Raquez, J.-M.; Dubois, P.; Kenny, J. M.; Peponi, L., Thermal and composting degradation of EVA/Thermoplastic starch blends and their nanocomposites. Polymer Degradation and Stability 2019, 159, 184-198.

Giannakas, A.; Vlacha, M.; Salmas, C.; Leontiou, A.; Katapodis, P.; Stamatis, H.; Barkoula, N.-M.; Ladavos, A., Preparation, characterization, mechanical, barrier and antimicrobial properties of chitosan/PVOH/clay nanocomposites. Carbohydrate polymers 2016, 140, 408-415.

39. Abdullah, Z. W.; Dong, Y., Biodegradable and water resistant poly (vinyl) alcohol (PVA)/starch (ST)/glycerol (GL)/halloysite nanotube (HNT) nanocomposite films for sustainable food packaging. Frontiers in materials 2019, 6, 58.

40. Pandey, J. K.; Singh, R. P., Green nanocomposites from renewable resources: effect of plasticizer on the structure and material properties of clay-filled starch. Starch-Stärke 2005, 57, (1), 8-15. 
41. Ojogbo, E.; Jardin, J.; Mekonnen, T. H., Robust and sustainable starch ester nanocomposite films for packaging applications. Industrial Crops and Products 2021, 160, 113153.

42. Tian, H.; Wang, K.; Liu, D.; Yan, J.; Xiang, A.; Rajulu, A. V., Enhanced mechanical and thermal properties of poly (vinyl alcohol)/corn starch blends by nanoclay intercalation. International journal of biological macromolecules 2017, 101, 314-320.

43. Mali, S.; Grossmann, M. V. E.; García, M. A.; Martino, M. N.; Zaritzky, N. E., Barrier, mechanical and optical properties of plasticized yam starch films. Carbohydrate Polymers 2004, 56, (2), 129-135. 